\title{
Reduction of Active Power Loss byUsing Adaptive Cat Swarm Optimization
}

\author{
K Lenin, B Ravindhranath Reddy \\ Jawaharlal Nehru Technological University Kukatpally, \\ Hyderabad 500 085, India \\ email: gklenin@gmail.com
}

\begin{abstract}
This paper presents, an Adaptive Cat Swarm Optimization (ACSO) for solving reactive power dispatch problem. Cat Swarm Optimization (CSO) is one of the new-fangled swarm intelligence algorithms for finding the most excellent global solution. Because of complication, sometimes conventional CSO takes a lengthy time to converge and cannot attain the precise solution. For solving reactive power dispatch problem and to improve the convergence accuracy level, we propose a new adaptive CSO namely 'Adaptive Cat Swarm Optimization' (ACSO). First, we take account of a new-fangled adaptive inertia weight to velocity equation and then employ an adaptive acceleration coefficient. Second, by utilizing the information of two previous or next dimensions and applying a new-fangled factor, we attain to a new position update equation composing the average of position and velocity information. TheprojectedACSO has been tested on standard IEEE 57 bus test system and simulation results shows clearly about the highquality performance of the plannedalgorithm in tumbling the real power loss.
\end{abstract}

Keywords: Optimal Reactive Power, Transmission loss, Adaptive cat swarmoptimization

\section{Introduction}

Optimal reactive power dispatch (ORPD) problem is multi-objective optimization problems that reduce the real power loss. Various mathematical techniqueslike the gradient method [1-2], Newton method [3] and linear programming [4-7] have been adopted to solve the optimal reactive power dispatch problem. Both the gradient and Newton methods has the difficulty in managing inequality constraints. If linear programming is applied then the inputoutput function has to be articulated as a set of linear functions which mostly lead to loss of accurateness. The problem of voltage stability and collapse play a major role in power system planning and operation [8]. Global optimization has received widespread research awareness, and a great number of methods have been applied to solve this problem. Evolutionary algorithms such as genetic algorithm have been already proposed to solve the reactive power flow problem $[9,10]$. Evolutionary algorithm is a heuristic approach used for minimization problems by utilizing nonlinear and non-differentiable continuous space functions. In [11], Genetic algorithm has been used to solve optimal reactive power flow problem. In [12], Hybrid differential evolution algorithm is proposed to improve the voltage stability index. In [13] Biogeography Based algorithm is projected to solve the reactive power dispatch problem. In [14], afuzzy based method is used to solve the optimal reactive power scheduling method .In [15], an improved evolutionary programming is used to solvethe optimal reactive power dispatch problem. In [16], the optimal reactive power flow problem is solved by integrating a genetic algorithm with a nonlinearinterior point method. In [17], apattern algorithm is used to solve ac-dc optimal reactive powerflow model with the generator capability limits. In [18], proposes a twostep approach to evaluate Reactive power reserves with respect to operating constraints and voltage stability. In [19], a programming based proposed approach used to solve the optimal reactive power dispatch problem. In [20], presents aprobabilistic algorithm for optimal reactive power provisionin hybrid electricity markets with uncertain loads. Cat Swarm Optimization (CSO) which mimics the behaviour of cats [21]. By imitate the behaviour of cats and modelling into two modes, CSO can decipher the optimization problems. So in this paper, we plan an Adaptive CSO in order to attain the elevated convergence accuracy in a lesser amount of iteration. First we employ an adaptive inertia weight and adaptive acceleration coefficient. So, the new velocity update equation will be calculated in an adaptive formula. Then, our aim is to consider the effect of previous or next steps in order to compute the current position. So by 
utilizing a factor namely 'Forgetting Factor', information values of steps will be dissimilar. Finally, we use an average form of position update equation composing new velocity and position information. The proposed algorithm ACSO been evaluated in standard IEEE 57 bus test system \& the simulation results shows that our proposed approach outperforms all reported algorithms in minimization of real power loss.

\section{Problem Formulation}

The OPF problem is measured as a general minimization problem with constraints, and can be mathematically written in the following form:

$$
\begin{aligned}
& \text { Minimize } f(x, u) \\
& \text { Subject to } g(x, u)=0
\end{aligned}
$$

and

$$
\mathrm{h}(\mathrm{x}, \mathrm{u}) \leq 0
$$

Where $f(x, u)$ is the objective function. $g(x . u)$ and $h(x, u)$ are respectively the set of equality and inequality constraints. $x$ is the vector of state variables, and $u$ is the vector of control variables.

The state variables are the load buses ( $P Q$ buses) voltages, angles, the generator reactive powers and the slack active generator power:

$$
\mathrm{x}=\left(\mathrm{P}_{\mathrm{g} 1}, \theta_{2}, \ldots, \theta_{\mathrm{N}}, \mathrm{V}_{\mathrm{L} 1}, ., \mathrm{V}_{\mathrm{LNL}}, \mathrm{Q}_{\mathrm{g} 1}, \ldots, \mathrm{Q}_{\mathrm{gng}}\right)^{\mathrm{T}}
$$

The control variables are the generator bus voltages, the shunt capacitors/reactors and the transformers tap-settings:

$$
\mathrm{u}=\left(\mathrm{V}_{\mathrm{g}}, \mathrm{T}, \mathrm{Q}_{\mathrm{c}}\right)^{\mathrm{T}}
$$

or

$$
\mathrm{u}=\left(\mathrm{V}_{\mathrm{g} 1}, \ldots, \mathrm{V}_{\mathrm{gng}}, \mathrm{T}_{1}, \ldots, \mathrm{T}_{\mathrm{Nt}}, \mathrm{Q}_{\mathrm{c} 1}, \ldots, \mathrm{Q}_{\mathrm{cNc}}\right)^{\mathrm{T}}
$$

Where $\mathrm{Ng}, \mathrm{Nt}$ and $\mathrm{Nc}$ are the number of generators, number of tap transformers and the number of shunt compensators respectively.

\section{Objective Function}

\section{Active power loss}

The objective of the reactive power dispatch is to minimize the active power loss in the transmission network, which can be described as follows:

$$
\mathrm{F}=\mathrm{PL}=\sum_{\mathrm{k} \in \mathrm{Nbr}} \mathrm{g}_{\mathrm{k}}\left(\mathrm{V}_{\mathrm{i}}^{2}+\mathrm{V}_{\mathrm{j}}^{2}-2 \mathrm{~V}_{\mathrm{i}} \mathrm{V}_{\mathrm{j}} \cos \theta_{\mathrm{ij}}\right)
$$

or

$$
\mathrm{F}=\mathrm{PL}=\sum_{\mathrm{i} \in \mathrm{Ng}} \mathrm{P}_{\mathrm{gi}}-\mathrm{P}_{\mathrm{d}}=\mathrm{P}_{\text {gslack }}+\sum_{\mathrm{i} \neq \text { slack }}^{\mathrm{Ng}} \mathrm{P}_{\mathrm{gi}}-\mathrm{P}_{\mathrm{d}}
$$

Where $g_{k}$ : is the conductance of branch between nodes $i$ and $j, N_{b r}$ : is the total number of transmission lines in power systems. Pd: is the total active power demand, $\mathrm{P}_{\mathrm{gi}}$ : is the generator active power of unit $i$, and $P_{\text {gsalck }}$ : is the generator active power of slack bus. 


\section{Voltage profile improvement}

For minimizing the voltage deviation in $\mathrm{PQ}$ buses, the objective function becomes:

$\mathrm{F}=\mathrm{PL}+\omega_{\mathrm{v}} \times \mathrm{VD}$

Where $\omega v$ : is a weighting factor of voltage deviation.

$\mathrm{VD}$ is the voltage deviation given by:

$$
\mathrm{VD}=\sum_{\mathrm{i}=1}^{\mathrm{Npq}}\left|\mathrm{V}_{\mathrm{i}}-1\right|
$$

\section{Equality Constraint}

The equality constraint $\mathrm{g}(\mathrm{x}, \mathrm{u})$ of the ORPD problem is represented by the power balance equation, where the total power generation must cover the total power demand and the power losses:

$$
P_{G}=P_{D}+P_{L}
$$

This equation is solved by running Newton Raphson load flow method, by calculating the active power of slack bus to determine active power loss.

\section{Inequality Constraints}

The inequality constraints $h(x, u)$ reflect the limits on components in the power system as well as the limits created to ensure system security. Upper and lower bounds on the active power of slack bus, and reactive power of generators:

$$
\begin{aligned}
& \mathrm{P}_{\mathrm{gslack}}^{\min } \leq \mathrm{P}_{\mathrm{gslack}} \leq \mathrm{P}_{\mathrm{gslack}}^{\max } \\
& \mathrm{Q}_{\mathrm{gi}}^{\min } \leq \mathrm{Q}_{\mathrm{gi}} \leq \mathrm{Q}_{\mathrm{gi}}^{\max }, \mathrm{i} \in \mathrm{N}_{\mathrm{g}}
\end{aligned}
$$

Upper and lower bounds on the bus voltage magnitudes:

$$
V_{i}^{\min } \leq V_{i} \leq V_{i}^{\max }, i \in N
$$

Upper and lower bounds on the transformers tap ratios:

$$
\mathrm{T}_{\mathrm{i}}^{\min } \leq \mathrm{T}_{\mathrm{i}} \leq \mathrm{T}_{\mathrm{i}}^{\max }, \mathrm{i} \in \mathrm{N}_{\mathrm{T}}
$$

Upper and lower bounds on the compensators reactive powers:

$$
\mathrm{Q}_{\mathrm{c}}^{\min } \leq \mathrm{Q}_{\mathrm{c}} \leq \mathrm{Q}_{\mathrm{C}}^{\max }, \mathrm{i} \in \mathrm{N}_{\mathrm{C}}
$$

Where $\mathrm{N}$ is the total number of buses, NT is the total number of Transformers; Nc is the total number of shunt reactive compensators.

\section{Cat Swarm Optimization}

Cat Swarm Optimization is a new-fangled optimization algorithm in the field of swarm intelligence. The CSO algorithm replica the behaviour of cats into two modes: 'Search mode' and 'Trace mode'. Swarm is made of primary population composed of particles to explore in the solution space. Here in CSO, we employ cats as particles for solving the problem. In CSO, each cat has its own location composed of $D$ dimensions, velocities for every dimension, a fitness value, which represents the accommodation of the cat to the fitness function, and a flag to identify whether the cat is in search mode or trace mode. The final solution would be the most excellent position of one of the cats. The CSO keeps the best solution until it reaches the end of the iterations [22]. 


\section{Search mode}

For modelling the behaviour of cats in resting time and being-alert, we use the search mode. In this mode is a time for opinion and deciding about next move. This mode has four main parameters which are mentioned as follow: search memory pools (SMP), search range of the selected dimension (SRD), calculate of dimension to change (CDC) and self-position consideration (SPC).

The process of search mode is describes as follow:

Step 1: create $\mathrm{j}$ copies of the present location of $\mathrm{cat}_{\mathrm{k}}$, where $\mathrm{j}=\mathrm{SMP}$. If the value of SPC is true, let $\mathrm{j}=(\mathrm{SMP}-1)$, then preserve the present location as one of the candidates.

Step 2: For every copy, according to CDC, arbitrarily Add or Subtract SRD percent the present values and reinstate the old ones.

Step 3: compute the fitness values (FS) of all candidate points.

Step 4: If all FS are not exactly equal, compute the selecting probability of every candidate point by (1), or else set all the selecting probability of every candidate point is 1.

Step 5: arbitrarily choose the point to move to from the candidate points, and replace the location of cat .

$$
P_{i}=\frac{\left|S S E_{i}-S S E_{\max }\right|}{S S E_{\max }-S S E_{\min }}
$$

If the objective of the fitness function is to discover the minimum solution, $F S_{b}=F S_{\max }$, otherwise $\mathrm{FS}_{\mathrm{b}}=\mathrm{FS}_{\mathrm{min}}$

\section{Trace Mode}

Trace mode is the second mode of algorithm. In this mode, cats craving to trace targets and foods. The procedure of trace mode can be described as follow:

Step 1: renew the velocities for each dimension according to (18).

Step 2: verify if the velocities are in the range of maximum velocity. In case the new velocity is over-range, it is set equal to the limit.

$$
\mathrm{V}_{\mathrm{k}, \mathrm{d}}=\mathrm{V}_{\mathrm{k}, \mathrm{d}}+\mathrm{r}_{1} \mathrm{c}_{1}\left(\mathrm{X}_{\mathrm{best}, \mathrm{d}}-\mathrm{X}_{\mathrm{k}, \mathrm{d}}\right)
$$

Step 3: renew the location of $\mathrm{cat}_{\mathrm{k}}$ according to equation (19)

$$
X_{k, d}=X_{k, d}+V_{k, d}
$$

$X_{\text {best,d }}$ is the position of the cat, who has the best fitness value, $X_{k, d}$ is the position of cat $t_{k}, c_{1}$ is an acceleration coefficient for extending the velocity of the cat to move in the solution space and usually is equal to 2.03 and $r_{1}$ is a random value uniformly generated in the range of $[0,1]$.

\section{Key explanation of CSO}

In order to merge the two modes into the algorithm, we define a mixture ratio (MR) which specifies the rate of mixing of search mode and trace mode. This parameter makes a decision how many cats will be moved into search mode procedure.First of all, we generate $\mathrm{N}$ cats and initialize the positions, velocities and the flags for cats. $\left(^{*}\right)$ According to the fitness function, calculate the fitness value of the each cat and keep the best cat into memory $\left(X_{\text {best }}\right)$. In next step, according to cat's flag, apply cat to the search mode or trace mode procedure. After finishing the associated progression, re-pick the number of cats and set them into search mode or trace mode according to MR parameter. At the end, check the termination condition, if satisfied, stop the program, and otherwise go to $\left(^{*}\right)$ [23].

\section{Adaptive Cat Swarm Optimization}

The trace mode of CSO has two equations: velocity update equation and position update equation. For attainment an adaptive CSO, we modify some of the parameters in velocity equation. Also to calculate the current location of cats, we deem the information of previous and next dimensions by using an extraordinary factor and then we attain a fresh

IJEEI Vol. 2, No. 3, September 2014 : 111 - 118 
dynamic position update equation. We explain the proposed algorithm in two parts.

\section{By means of Adaptive Parameters}

In the proposed algorithm, we insert an adaptive inertia weight to the velocity equation which is updated in every dimension. By utilizing this parameter, we create equilibrium between global and local search ability. A large inertia weight make easy of a global search while a small inertia weigh make easy of a local search. First we employ a large value and it will be reduced gradually to the least value by using (20).

$$
W(i)=W_{s}+\frac{i_{\max }-i}{2 \times i_{\max }}
$$

Equation (20) specifies that the inertia weight will be renewed adaptively, where Ws is the starting weight, $i_{\max }$ is the maximum dimension of benchmark and $i$ is the existing dimension. So the maximum inertia weight happens in the primary dimension of the each iteration and it will be updated decreasingly in each dimension. In the projected algorithm Ws is equal to 0.5 . Also, $\mathrm{c} 1$ is an acceleration coefficient for extending the velocity of the cat to shift in the solution space. This parameter is a constant value and is usually equal to 2.03 , but we use an adaptive formula to update it by (21).

$$
C(i)=C_{s}+\frac{i_{\max }-i}{2 \times i_{\max }}
$$

Equation (21) reveals that the adaptive acceleration coefficient will be steadily increased in each dimension and the greatest value happens in the last dimension. Here Cs is equal to 2.03 .

By using these two adaptive parameters, we modify the velocity update equation for each cat to a new form describing in (22).

$$
\mathrm{V}_{\mathrm{k}, \mathrm{d}}=\mathrm{W}(\mathrm{d}) \times \mathrm{V}_{\mathrm{k}, \mathrm{d}}+\mathrm{r}_{1} \times \mathrm{C}(\mathrm{d}) \times\left(\mathrm{X}_{\mathrm{best}, \mathrm{d}}-\mathrm{X}_{\mathrm{k}, \mathrm{d}}\right)
$$

\section{Fresh Dynamic location Update Equation}

In this part, we modify the location update equation to a new form. In the conventional $\mathrm{CSO}$, the position of cat is including of current information of velocity and position. Occasionally in many cases, using of previous information in order to guess the current position is useful. Also, taking the advantages of next information can be suitable information for renewing the cat's position. So we use the two previous or next dimensions information of velocity and position by applying a fresh factor which is called 'Forgetting factor'. By this factor, the values of previous and next steps will be different. So the information value for first previous or next step is senior than second previous or next step. It means that the pressure of previous or next step is more significant than previous or next second step. New-fangled position update equation is described by (23). In the projected algorithm, $y$ is the forgetting factor and is equal to 0.8 (It is necessary to use $y>0.5$ ). This fresh position update equation is composing two new vibrant terms, average location information and average velocity information. Here, we employ the current and the average information of first and second previous or next dimensions for both velocity and position by applying a forgetting factor $(\mathrm{Y})$.

$\mathrm{X}_{\mathrm{k}, \mathrm{d}}=\frac{1}{2}$ [location inofrmation + velocity information $]$

location information $=X_{k, d}+\frac{\left(\gamma \times X_{k, d+1}\right)+(1-\gamma) \times\left(X_{K, d+2}\right)}{2}+\frac{\left(\gamma \times X_{k, d-1}\right)+(1-\gamma) \times\left(X_{K, d-2}\right)}{2}$

velocity information $=\mathrm{V}_{\mathrm{k}, \mathrm{d}}+\frac{\left(\gamma \times \mathrm{V}_{\mathrm{k}, \mathrm{d}+1}\right)+(1-\gamma) \times\left(\mathrm{V}_{\mathrm{K}, \mathrm{d}+2}\right)}{2}+\frac{\left(\gamma \times \mathrm{V}_{\mathrm{k}, \mathrm{d}-1}\right)+(1-\gamma) \times\left(\mathrm{V}_{\mathrm{K}, \mathrm{d}-2}\right)}{2}$

\section{Simulation Results}

The proposed ACSO algorithm for solving ORPD problem is tested for standard IEEE57 bus power system. The IEEE 57-bus system data consists of 80 branches, seven generatorbuses and 17 branches under load tap setting transformer branches. The possible reactive 
power compensation buses are 18, 25 and 53. Bus 2, 3, 6, 8, 9 and 12 are PV buses and bus 1 is selected as slack-bus. In this case, the search space has 27 dimensions, i.e., the seven generator voltages, 17 transformer taps, and three capacitor banks. The system variable limits are given in Table 1. The initial conditions for the IEEE-57 bus power system are given as follows:

Pload $=12.221$ p.u. Qload $=3.251$ p.u.

The total initial generations and power losses are obtained as follows:

$\sum \mathrm{P}_{\mathrm{G}}=12.6259$ p.u. $\sum \mathrm{Q}_{\mathrm{G}}=3.3369$ p.u.

Ploss $=0.26493$ p.u. Qloss $=-1.2209$ p.u.

Table 2 shows the various system control variables i.e. generator bus voltages, shunt capacitances and transformer tap settings obtained after ACSO based optimization which are within their acceptable limits. In Table 3, a comparison of optimum results obtained from proposed ACSO with other optimization techniques for ORPD mentioned in literature for IEEE57 bus power system is given. These results indicate the robustness of proposed ACSO approach for providing better optimal solution in case of IEEE-57 bus system.

Table 1. Variables limits for ieee-57 bus power system (p.u.)

\begin{tabular}{cccccccc}
\hline \multicolumn{7}{c}{ reactive power generation limits } \\
\hline bus no & 1 & 2 & 3 & 6 & 8 & 9 & 12 \\
$\mathrm{Q}_{\text {gmin }}$ & -1.2 & -.013 & -.03 & -0.06 & -1.2 & -0.02 & -0.3 \\
$\mathrm{q}_{\text {gmax }}$ & 2 & 0.6 & 0.5 & 0.23 & 2 & 0.03 & 1.43 \\
\hline \multicolumn{7}{c}{ voltage and tap setting limits } \\
\hline $\mathrm{v}_{\text {gmin }}$ & $\mathrm{v}_{\mathrm{gmax}}$ & $\mathrm{v}_{\text {pqmin }}$ & $\mathrm{v}_{\text {pqmax }}$ & $\mathrm{t}_{\mathrm{kmin}}$ & $\mathrm{t}_{\mathrm{kmax}}$ \\
0.8 & 1.0 & 0.93 & 1.06 & 0.6 & 1.2 \\
\hline \multicolumn{7}{c}{ shunt capacitor limits } \\
\hline bus no & 18 & 25 & 53 \\
$\mathrm{q}_{\mathrm{cmin}}$ & 0 & 0 & 0 \\
$\mathrm{q}_{\mathrm{cmax}}$ & 10 & 5.3 & 6.2 \\
\hline
\end{tabular}

Table 2. Control variables obtained after optimization by ACSO method for

\begin{tabular}{cc}
\multicolumn{2}{c}{ iee-57 bus system (p.u.) } \\
\hline \multicolumn{2}{c}{ Control } \\
Variables & ACSO \\
\hline V1 & 1.1 \\
V2 & 1.078 \\
V3 & 1.064 \\
V6 & 1.057 \\
V8 & 1.078 \\
V9 & 1.044 \\
V12 & 1.058 \\
Qc18 & 0.0835 \\
Qc25 & 0.326 \\
Qc53 & 0.0615 \\
T4-18 & 1.017 \\
T21-20 & 1.068 \\
T24-25 & 0.968 \\
T24-26 & 0.936 \\
T7-29 & 1.095 \\
T34-32 & 0.948 \\
T11-41 & 1.016 \\
T15-45 & 1.068 \\
T14-46 & 0.936 \\
T10-51 & 1.044 \\
T13-49 & 1.065 \\
T11-43 & 0.913 \\
T40-56 & 0.906 \\
T39-57 & 0.968 \\
T9-55 & 0.988 \\
\hline
\end{tabular}

IJEEI Vol. 2, No. 3, September $2014: 111-118$ 
Table 3. comparative optimization results for ieee- 57 bus power system (p.u.)

\begin{tabular}{clccc}
\hline S.No. & \multicolumn{1}{c}{$\begin{array}{c}\text { Optimization } \\
\text { Algorithm }\end{array}$} & $\begin{array}{c}\text { Best } \\
\text { Solution }\end{array}$ & Worst Solution & $\begin{array}{c}\text { Average } \\
\text { Solution }\end{array}$ \\
\hline 1 & NLP [24] & 0.25902 & 0.30854 & 0.27858 \\
2 & CGA [24] & 0.25244 & 0.27507 & 0.26293 \\
3 & AGA [24] & 0.24564 & 0.26671 & 0.25127 \\
4 & PSO-w [24] & 0.24270 & 0.26152 & 0.24725 \\
5 & PSO-cf [24] & 0.24280 & 0.26032 & 0.24698 \\
6 & CLPSO [24] & 0.24515 & 0.24780 & 0.24673 \\
7 & SPSO-07 [24] & 0.24430 & 0.25457 & 0.24752 \\
8 & L-DE [24] & 0.27812 & 0.41909 & 0.33177 \\
9 & L-SACP-DE [24] & 0.27915 & 0.36978 & 0.31032 \\
10 & L-SaDE [24] & 0.24267 & 0.24391 & 0.24311 \\
11 & SOA [24] & 0.24265 & 0.24280 & 0.24270 \\
12 & LM [25] & 0.2484 & 0.2922 & 0.2641 \\
13 & MBEP1 [25] & 0.2474 & 0.2848 & 0.2643 \\
14 & MBEP2 [25] & 0.2482 & 0.283 & 0.2592 \\
15 & BES100 [25] & 0.2438 & 0.263 & 0.2541 \\
16 & BES200 [25] & 0.3417 & 0.2486 & 0.2443 \\
17 & Proposed ACSO & 0.22321 & 0.23984 & 0.23199 \\
\hline
\end{tabular}

\section{Conclusion}

In this paper, the ACSO has been productively implemented to solve ORPD problem. The main advantages of the ACSO to the ORPD problem are optimization of different type of objective function, real coded of both continuous and discrete control variables, and easily handling nonlinear constraints. The proposed algorithm has been tested on the IEEE 57-bus system. The active power loss has been minimized andthe voltage profile indexes are within the limits.

\section{References}

[1] O Alsac, and B Scott. "Optimal load flow with steady state security". IEEE Transaction. PAS-1973: 745-751.

[2] Lee KY, Paru YM, Oritz JL. A united approach to optimal real and reactive power dispatch. IEEE Transactions on power Apparatus and systems. 1985; PAS-104: 1147-1153

[3] A Monticelli, MVF Pereira, and S Granville. "Security constrained optimal power flow with post contingency corrective rescheduling". IEEE Transactions on Power Systems. 1987; PWRS-2(1): 175182.

[4] Deeb N, Shahidehpur SM. Linear reactive power optimization in a large power network using the decomposition approach. IEEE Transactions on power system. 1990; 5(2): 428-435

[5] E Hobson. 'Network consrained reactive power control using linear programming'. IEEE Transactions on power systems. 1980; PAS-99(4): 868-877.

[6] KY Lee, YM Park, and JL Oritz. "Fuel -cost optimization for both real and reactive power dispatches". IEE Proc. 131C(3): 85-93.

[7] MK Mangoli, and KY Lee. "Optimal real and reactive power control using linear programming". Electr. Power Syst. Res. 1993; 26: 1-10.

[8] CA Canizares, ACZ de Souza and VH Quintana. "Comparison of performance indices for detection of proximity to voltage collapse". 1996; 11(3): 1441-1450.

[9] SR Paranjothi, and K Anburaja. "Optimal power flow using refined genetic algorithm". Electr.Power Compon. Syst. 2002; 30: 1055-1063.

[10] D Devaraj, and B Yeganarayana. "Genetic algorithm based optimal power flow for security enhancement". IEE proc-Generation. Transmission and Distribution. 152, 2005.

[11] A Berizzi, C Bovo, M Merlo, and M Delfanti. "A ga approach tocompare orpf objective functions including secondary voltage regulation". Electric Power Systems Research. 2012; 84(1): 187 - 194.

[12] CF Yang, GG Lai, CH Lee, CT Su, and GW Chang. "Optimalsetting of reactive compensation devices with an improved voltagestability index for voltage stability enhancement". International Journal of Electrical Power and Energy Systems. 2012; 37(1): 50 - 57.

[13] P Roy, S Ghoshal, and S Thakur. "Optimal var control for improvementsin voltage profiles and for real power loss minimization usingbiogeography based optimization". International Journal of ElectricalPower and Energy Systems. 2012; 43(1): 830 - 838.

[14] B Venkatesh, G Sadasivam, and M Khan. "A new optimal reactivepower scheduling method for loss minimization and voltage stabilitymargin maximization using successive multi-objective fuzzy Ip technique". IEEE Transactions on Power Systems. 2000; 15(2): 844 -851. 
[15] W Yan, S Lu, and D Yu. "A novel optimal reactive power dispatchmethod based on an improved hybrid evolutionary programming technique". IEEE Transactions on Power Systems. 2004; 19(2): 913 $-918$.

[16] W Yan, F Liu, C Chung, and K Wong. "A hybrid genetic algorithminteriorpoint method for optimal reactive power flow". IEEE Transactionson Power Systems. 2006; 21(3): 1163 -1169.

[17] J Yu, W Yan, W Li, C Chung, and $\mathrm{K}$ Wong. "An unfixed piecewiseoptimalreactive power-flow model and its algorithm for ac-dc systems". IEEE Transactions on Power Systems. 2008; 23(1): $170-176$.

[18] F Capitanescu. "Assessing reactive power reserves with respect tooperating constraints and voltage stability". IEEE Transactions on Power Systems. 2011; 26(4): 2224-2234.

[19] Z Hu, X Wang, and G Taylor. "Stochastic optimal reactive powerdispatch: Formulation and solution method". International Journal of Electrical Power and Energy Systems. 2010; 32(6): 615 - 621.

[20] A Kargarian, M Raoofat, and M Mohammadi. "Probabilistic reactivepower procurement in hybrid electricity markets with uncertain loads". Electric Power Systems Research. 2012; 82(1): 68 - 80.

[21] Chu SC, Tsai PW and Pan JS. Cat Swarm Optimization, LNAI 4099, Berlin Heidelberg: SpringerVerlag. 2006: 3(1): 854- 858.

[22] Santosa B, and Ningrum M. Cat Swarm Optimization for Clustering. International Conference of Soft Computing and Pattern Recognition. 2009: 54-59.

[23] Orouskhani M, Mansouri M and Teshnehlab M. Average-Inertia weighted Cat swarm optimization. LNCS, Berlin Heidelberg: Springer-Verlag. 2011: 321- 328.

[24] Chaohua Dai, Weirong Chen, Yunfang Zhu, and Xuexia Zhang. "Seeker optimization algorithm for optimal reactive power dispatch". IEEE Trans. Power Systems. 2009; 24(3): 1218-1231.

[25] JR Gomes and OR Saavedra. "Optimal reactive power dispatch using evolutionary computation: Extended algorithms". IEE Proc.-Gener. Transm. Distrib. 1999; 146(6). 